\title{
Externalidades e mudanças da regulamentação ambiental para a suinocultura norte-americana: é possível no caso brasileiro? ${ }^{1}$
}

Celso Leonardo Weydmann²

Resumo: Neste trabalho objetiva-se descrever a relação entre externalidade e regulação ambiental com base no desenvolvimento recente da suinocultura norte-americana para avaliar a possibilidade de uma reforma na legislação que permita um controle ambiental mais rigoroso dos dejetos da suinocultura brasileira. A análise evidenciou que se a reforma fosse feita aos moldes da norte-americana teria que ser uma iniciativa do governo federal para definir metas nacionais de padrões polutivos com base na consolidação de regras estaduais. Recursos públicos seriam necessários para fiscalizar e punir poluidores, e para financiar os produtores na aquisição dos insumos ambientais. Por outro lado, as pressões da sociedade estariam restritas à atuação de organizações isoladas de pesquisa e extensão. A conclusão é de que no curto-prazo não há condições econômicas, sociais e institucionais que apontem para a realização de reforma.

Palavras-chaves: suinocultura, externalidades, regulamentação, meio ambiente, Estados Unidos.

Classificação JEL: Q24

\footnotetext{
${ }^{1}$ Pesquisa feita na Purdue University (EUA) com recursos da bolsa de pós-doutorado do CNPq. O autor agradece os comentários de Francisco Gelinski, Hugo Gosman, Laércio Pereira e Lauro Mattei, e de três pareceristas anônimos, isentando-os, todavia, de qualquer erro ou omissão remanescente no texto.

${ }^{2}$ Professor do Depto. Ciências Econômicas da UFSC. E-mail: celsolw@cse.ufsc.br
} 
Abstract: This paper describes the relationship between externalities and environmental regulation in the USA hog sector to verify the possibility to increase the stringency of regulation concerning externalities caused by hog manure in Brazil. The analysis shows that if the regulation reform in Brazil is going to follow the one in the USA it should be a government iniciative through the definition of national polluting standards based on hog manure rules already in place by the Brazilian states. Public funds would be required to enforce and punish polluters, and also to support farmers to acquire environmental inputs. On the other side, social pressure would be confined from the action of isolated groups related to environment, agriculture and farmer's work extension. The main conclusion is that there are no economic, social and institutional factors indicating the feasibility of such reform in the short run.

Key words: hog sector, externalities, regulation, environment, USA.

\section{JEL classification: Q24}

\section{Introdução}

Reformas impondo maiores restrições na regulamentação ambiental sobre os dejetos da suinocultura foram realizadas em diversos países desenvolvidos nesta última década. Incluem-se países com escassez de área para depositar os dejetos, a exemplo dos europeus e Japão, e mesmo aqueles que possuem ampla extensão territorial, como Estados Unidos e Canadá, tendo ocorrido, inclusive, proibição à expansão do setor em alguns países ${ }^{3}$. A poluição por dejetos, que atinge a água e o ar, ampliou-se, de um lado, pela expansão das áreas urbanas, e de outro, pelo aumento do número de animais confinados por exploração, visando obter economias de escala ${ }^{4}$.

\footnotetext{
${ }^{3}$ Uma visão das regras ambientais à suinocultura em vários países é encontrada em BEGHIN \& METCALFE (1998).

${ }^{4}$ Os dejetos diários de um suíno adulto equivalem ao de quatro pessoas. Para uma descrição da relação especialização, concentração e poluição na suinocultura vide CAMPOS (1995).
} 
Há indicações de que a regulamentação para a suinocultura brasileira é menos restritiva do que a norte-americana (WEYDMANN, 2002) ${ }^{5}$. Esta constatação parece confirmar o senso comum de que os nossos problemas ambientais neste setor não tem a gravidade do norte-americano, e daí não haveria necessidade de se reavaliar a atual legislação. Esta afirmação, entretanto, pode ser questionada. Primeiro, há problemas sérios com dejetos, sendo mais conhecidos os enfrentados na região Oeste catarinense, produtora de cerca de $80 \%$ das exportações brasileiras de carne suína (TESTA et al., 1996). Segundo, é incipiente a estratégia governamental de ampliar o mercado para as exportações através da regulamentação ambiental (MMA, 2001). As exportações de carnes suínas atualmente se concentram no problemático mercado russo, e não são aceitas no mercado europeu e japonês devido ao problema da febre aftosa. Estas barreiras sanitárias podem ser acrescidas das ambientais no futuro. Por exemplo, países exportadores como os Estados Unidos, que possuem uma regulamentação ambiental restrita e custosa à produção, poderiam alegar dumping ambiental à concorrência brasileira devido a regras inadequadas (GONÇALVES, 1998). Terceiro, é inexorável o crescimento da produção via economias de escala. Esta característica implica agravamento dos atuais problemas e é uma ameaça, por exemplo, à região pantaneira para onde confluem os rios, águas que banham algumas áreas do Centro-Oeste, regiões que tendem a abrigar a expansão do setor devido à produção de grãos e disponibilidade de amplas áreas que permitem a deposição dos dejetos das grandes explorações.

Portanto, parece necessário que se reflita sobre as externalidades na suinocultura brasileira e sua regulamentação. A questão endereçada neste estudo é: há no Brasil características sociais, institucionais e econômicas que possam levar a uma reforma das regras à semelhança do que ocorreu nos Estados Unidos?

Este trabalho tem por objetivo: a) descrever a relação entre externalidade e regulação ambiental no contexto do desenvolvimento recente da suinocultura norte-americana; b) analisar características desta relação que permitam discutir a possibilidade de um controle mais rigoroso no uso dos dejetos na suinocultura brasileira.

\footnotetext{
${ }^{5}$ Neste estudo são comparados procedimentos ambientais observados na suinocultura brasileira e americana.
} 
Externalidades e mudanças da regulamentação ambiental para a suinocultura norte-americana: é possível no caso brasileiro?

\section{Metodologia}

Este trabalho tem três seções. A primeira contém a revisão de literatura, que trata dos elementos analíticos deste estudo como externalidades, direitos de propriedade e regulamentação, os quais são, na segunda seção, descritos no desenvolvimento recente da suinocultura americana. Na terceira seção, estes elementos são analisados do ponto de vista institucional, social e econômico buscando avaliar a possibilidade de mudanças na regulamentação ambiental brasileira. As conclusões são expostas na quarta seção.

A suinocultura norte-americana é referência de comparação porque, à semelhança da brasileira, é uma das maiores exportadoras de carne suína, possui amplitude territorial, tem grande oferta de grãos, e a atividade tende a se concentrar na grande exploração. A diferença é que recentemente naquele país a regulamentação para a suinocultura foi reformulada, tornando-se mais restritiva. Esta mudança deveu-se não apenas à dimensão dos problemas existentes, mas também para manter o acesso a mercados compradores de carne suína com valor agregado como o Japão.

\section{A literatura sobre a relação externalidade e regulamentação}

A preocupação com o meio ambiente nos anos 80 deu origem à noção de sustentabilidade, que na agropecuária pode se caracterizar pela “...adoção de práticas e tecnologias que... mantenham a integridade ecológica dentro e fora da propriedade... preservam a biodiversidade,... e outros bens públicos não avaliados pelos mercados existentes..." segundo a OCDE (1994) apud BURTON et al.(1998:2). Os termos "prática e tecnologia' representam insumos ambientais transacionados no mercado (madeira, carvão, petróleo, cereais, etc.), e 'bens públicos' tratam dos serviços ambientais não transacionados como ar, água, capacidade de assimilação de rejeitos, paisagem, etc. (ROMEIRO, 1999).

A falta de sustentabilidade ambiental pode limitar o crescimento econômico em geral. Na exaustão de insumos ambientais, a elevação dos preços limita o uso dos mesmos, o que não acontece no caso dos serviços ambientais, cujo mercado não sinaliza a escassez, daí o conceito 
de externalidade. É negativa ${ }^{6}$ quando decisões de produção e de consumo afetam a disponibilidade dos serviços ambientais e reduzem o bem-estar ou a produção de outros. Sem indicador de escassez, a quantidade de externalidade produzida por um agente não alcançará um equilíbrio (eficiente) de Pareto porque o custo social da externalidade não é levado em conta pelo agente na decisão de produção.

Em termos técnicos, a externalidade indica que o agente ao produzir considera apenas o custo marginal privado ( $\mathrm{CMg}$ ) e não o custo incremental de poluir, denominado custo marginal externo (CME). A adição de ambos os custos resulta no custo marginal social (CMS). A inclinação do CMS é maior do que CMg, indicando maior custo incremental para uma unidade a mais de produção. Assim, a quantidade de poluição decorrente da produção de equilíbrio onde receita marginal $(\mathrm{RMg})=\mathrm{CMg}$ é maior comparativamente à condição RMg = CMS. Neste caso, a ineficiência de Pareto resulta de que $\mathrm{CMg}<\mathrm{CMS}$. Portanto, a externalidade negativa implica maior poluição devido à subestimação de custos e, em conseqüência, viabiliza a permanência no setor de agentes economicamente inviáveis caso houvesse a internacionalização do CME.

Havendo falha do mercado, o Estado pode intervir na tentativa de correção da externalidade sendo comum a incidência de imposto (taxação pigouviana) e ou a fixação de limites polutivos. Para ter um imposto eficiente, o Estado precisa conhecer o nível ótimo de poluição, o que dificilmente é possível (VARIAN, 1994). Além disso, o agente polui mais se o ganho adicional compensa a maior taxação. Portanto, o imposto não garante o controle polutivo dos agentes.

Os limites (ou padrões) permitem a definição dos níveis polutivos, possibilitando maior clareza na avaliação de uma transgressão, o que explica o seu amplo uso em atividades potencialmente capazes de causar danos ao meio ambiente?

As externalidades têm relação com os direitos de propriedade, cuja má definição dificulta que as pessoas negociem direitos à semelhança de uma transação comum (VARIAN,1994), o que pode levar à regulamentação. O direito de propriedade abrange o direito de uso, de contratar e

${ }^{6}$ Existem externalidades positivas, vide livro texto de microeconomia como VARIAN(1994).

${ }^{7}$ Uma visão alternativa de soluções na abordagem da economia ecológica está em ROMEIRO (1999) e MUELLER (1998). 
Externalidades e mudanças da regulamentação ambiental para a suinocultura norte-americana: é possível no caso brasileiro?

obter renda de um recurso e de transferir para terceiros os direitos sobre um recurso. Além disso, o direito tem respaldo nas regras sociais e de comportamento (EGGERTSSON,1990).

A conjunção de direitos de propriedade definidos e a inexistência de custos de transação fazem com que uma negociação, que envolva poucos poluidores e vítimas da poluição, alcance uma solução de eficiência paretiana, tornando-se desnecessária a regulamentação (COASE, 1960). Entretanto, as negociações quase sempre envolvem custos de transação para obter informações e também o mercado não funciona adequadamente devido, por exemplo, à impossibilidade de se aferir o CME quando a poluição é causada por um conjunto de pequenos produtores ou quando os poluidores têm poder político e econômico (COLMAN, 1994).

A indefinição dos direitos de propriedade pode fazer com que recursos de propriedade comum sejam superexplorados. Neste caso, o livre acesso dos agentes pode levar à exaustão dos recursos com perdas para todos, conhecido na literatura como a tragédia dos comuns. A solução mais uma vez pode estar na regulamentação, através de limites ao uso do recurso e também na aplicação de taxas ou ainda no controle privado do mesmo.

A regulamentação, ao depender fundamentalmente do Estado, é a melhor forma para delinear os direitos de propriedade (EGGERTSSON, 1990). Pode ser vista como "o conjunto de leis e controles administrativos que se originam do governo e afetam o funcionamento do mercado, interferindo, deste modo, na eficiência interna e alocativa das empresas e de indústrias" (SANTANA, 1995: 404).

A regulamentação serve aos interesses 'de quem tem poder de barganha...'(NORTH, 1990 apud ROMEIRO, 1999: 90) e cabe ao Estado atender estes grupos através de regras e da coordenação da ação coletiva (CARDIM,1999). Grupos de pressão para mudanças institucionais associadas com os efeitos das externalidades e da ampliação da conscientização ecológica existem apenas nos países desenvolvidos, segundo ARROW et al.(1995) apud ROMEIRO (1999: 80). Para Arrow, os indivíduos evoluem de uma visão da degradação ambiental como um mal necessário, para, com crescimento e melhoria do bem-estar, vê-la como prejudicial. Neste contexto é crescente a importância do terceiro setor (social empowerment), paralelamente aos interesses de outros grupos sociais, na pressão política sobre as instituições legisladoras. 
Denomina-se colapso regulatório quando a regulamentação é ineficiente para resolver os problemas para a qual se destina, ou quando gera problemas não intencionais na eficiência dos agentes. Para evitar o colapso, o regulador deve ter "independência, qualificação técnica e recursos materiais” (SANTANA, 1994: 406). Assim, nos países menos desenvolvidos a regulamentação contrária aos interesses de grupos políticos importantes tem grande chance de incorrer no colapso regulatório, colocando em dúvidas a garantia ao direito de propriedade.

Os elementos teóricos anteriores são contextualizados na suinocultura norte americana na próxima seção.

\section{Externalidades na suinocultura norte-americana}

As externalidades na suinocultura envolvem o ar, as águas de superfície e subterrâneas, ocorrendo de várias formas. O tratamento inadequado das lagoas de estabilização e da vegetação circunvizinha não impede a propagação dos gases nas propriedades adjacentes. Lagoas com capacidade insuficiente de retenção de dejetos podem, em ocasiões de chuva intensa e prolongada, vazar nas águas e rios próximos. Também existe o risco moral do produtor despejar parte ou a totalidade dos dejetos das lagoas nas águas públicas. Finalmente, o uso excessivo dos dejetos como fertilizante no solo pode comprometer os lençóis freáticos e, por extensão, os poços de água destinados ao consumo humano.

Estimativas para a suinocultura americana mostram que $75 \%$ das grandes e $15 \%$ das pequenas explorações produziram dejetos em excesso relativamente à capacidade de absorção de solos como fertilizante em $1997^{\circ}$. Por conta disso, a sobra de nitrogênio nos solos americanos aumentou em 20\% em 15 anos (GOLLEHON \& CASWELL, 2000).

Em 1996, o Estado da Carolina do Norte notabilizou-se ${ }^{9}$ pelo vazamento de grandes lagoas de contenção de dejetos ${ }^{10}$, contaminando os

\footnotetext{
${ }^{8}$ Os problemas relacionados com a presença dos dejetos na água podem ser vistos em USEPA, 2001c.

${ }^{9}$ A reportagem sobre esta matéria ganhou o Prêmio Pulitzer de imprensa no ano de 1996. Pode ser acessada no endereço: http://www.pulitzer.org/year/1996/public-service/works/about.html.

${ }^{10}$ A maior empresa produtora na época - Smithfields - enfrentou mais de 6.000 acusações de violação de regras ambientais no período 1991-97 e a unidade de Virgínia foi multada
} 
Externalidades e mudanças da regulamentação ambiental para a suinocultura norte-americana: é possível no caso brasileiro?

lençóis freáticos ao redor das explorações. Em 1999, novos problemas surgiram devido ao furacão Floyd, contaminando riachos e rios (SULLIVAN et al., 2000) ${ }^{11}$. O problema fez com que as autoridades decidissem pela suspensão de novas explorações por até um ano.

\subsection{Os direitos de propriedade e a oposição social à suinocultura}

Na suinocultura as externalidades atingem os direitos ao ar e águas limpos, afetando o direito à saúde das pessoas ${ }^{12}$. Também o direito de obter renda pode ser afetado na medida em que as externalidades reduzem os preços de propriedades próximas às áreas de produção suinícola (RHODES, 1998).

Devido ao comprometimento dos direitos de propriedade, e também preocupados com a sustentabilidade ambiental, grupos pressionam os legisladores por regulamentação com punição mais severa aos poluidores e mais restritiva com os projetos de ampliação e implantação de explorações suinícolas. Apenas na Carolina do Norte, um dos três maiores estados produtores, existem seis diferentes grupos ${ }^{13}$, que se identificam pela sigla NIMBY (not in my backyard) ${ }^{14}$. Os grupos também contam com o voluntariado da comunidade para vigiar as unidades produtoras, o que aumenta as chances de denúncias às autoridades.

Por outro lado os produtores, em geral, contam com o apoio de autoridades governamentais, que vêem na suinocultura uma oportunidade para atrair investimento e gerar empregos. $\mathrm{O}$ apoio se traduz em programas de apoio financeiro e formulação de regras ambientais pouco rigorosas. Os fatos acontecidos na Carolina do Norte em 1996 podem ser creditados ao colapso regulatório ambiental devido à influência política de sete dos

em US\$12 milhões, segundo a revista Successful Farming. A informação pode ser vista em http://www.agriculture.com/sfonline/sf/1997/october/pork97/pph97.html.

${ }^{11}$ Outros casos de vazamento de dejetos podem ser vistos em METCALFE (2000b, p. 519).

${ }^{12}$ Os efeitos do odor na saúde podem ser vistos no artigo Social Influences Afect Odor Perception na revista National Hog Farmer, de agosto de 1998 no site http://industryclick. com $/$ magazine.asp? siteid $=5 \&$ magazineid $=17$.

${ }^{13} \mathrm{O}$ site http://checc.sph.unc.edu/cfdocs/guidesearch/NewSearch.cfm descreve os grupos na Carolina do Norte.

${ }^{14}$ Um caso NIMBY está em http://www.thepigsite.com/backroom/default.asp?display = 60 datado de $17 /$ maio/2002. 
dez maiores grupos suinícolas americanos ${ }^{15}$, através de representantes no legislativo estadual ${ }^{16}$.

\subsection{A regulamentação norte-americana para controle das externalidades na suinocultura}

A primeira regulamentação sobre as águas públicas é o Clean Water Act aprovada em 1972, e que autoriza o Environmental Protection Agency $(\mathrm{EPA})^{17}$ tratar do licenciamento de produtores para controle dos resíduos nas águas através do programa National Pollutant Discharge Elimination System (NPDES). Posteriormente, o Ministério da Agricultura foi envolvido no problema (1990 USDA Water Quality Program) e a definição de regras para alocação recursos federais no controle da poluição surgiu em 1996 (1996 Environmental Quality Incentives Program) ${ }^{18}$.

Na década de 1990, 28 estados alteraram suas regulamentações, tornando-as mais rigorosas (METCALFE, 2000b). Em geral, estas regras atendem parte das pressões dos grupos ambientalistas prevendo, por exemplo, que os projetos de instalação ou ampliação da produção de suínos devam ser submetidos ao debate público antes da decisão oficial da autoridade $^{19}$. Além disso, as unidades de produção devem realizar teste geológico do solo, planejar os nutrientes das rações dos animais, formalizar o cumprimento da legislação e submeterem-se ao controle local. Para uma visão das regras dos estados vide MCMAHON et al. (1998).

Em 2002 um marco importante foi a revisão do NPDES, que consolidou as regras estaduais e impôs uma legislação com padrões federais para controle dos dejetos na suinocultura, avicultura e pecuária de

\footnotetext{
${ }^{15}$ A relação dos 25 maiores grupos americanos e suas respectivas bases de produção é encontrada em http://www.agriculture.com/sfonline/sf/2001/october/pork_powerhouses.pdf.

${ }^{16}$ A leitura da atuação de Wendel Murphy, senador do estado por 10 anos, e dirigente do maior grupo privado produtor de suínos nos Estados Unidos, e o favorecimento à suinocultura está no site da nota de rodapé $n^{\circ} .11$.

${ }^{17}$ A legislação que baseia a atuação do EPA pode ser acessada no endereço http://www. epa.gov/epahome/laws.htm.

${ }^{18}$ METCALFE (1999, p.5)

${ }^{19}$ Conforme respostas à questão nove da pesquisa National Survey of Animal Confinement Policies realizada em 1998. Os resultados estão no site http://cherokee.agecon. clemson.edu/confine.htm.
} 
- Externalidades e mudanças da regulamentação ambiental para a suinocultura norte-americana: é possível no caso brasileiro?

leite $^{20}$. Em resumo, ao governo federal cabe o controle das regras para o depósito de dejetos nas lagoas de contenção e aos estados compete observar os padrões de incorporação dos dejetos no solo como fertili$z^{2}{ }^{21}$. Os estados têm um prazo de até três anos para implementar os novos padrões ${ }^{22}$, já que são considerados mais restritivos segundo os produtore $^{23}$. Os ambientalistas, entretanto, consideram as regras aquém das expectativas, a exemplo do grupo Farmweb ${ }^{24}$.

Recursos para a reforma ambiental foram alocados no plano 2002 Farm Security and Rural Investment $A c t^{25}$, de cuja verba recorde para melhoria ambiental de US\$ 17 bilhões $^{26}$, destinou US\$ 6,6 bilhões aos problemas das atividades relacionadas com confinamento. Destaca-se no plano o Environment Quality Incentives Program (EQIP), que disponibiliza recursos para os produtores atenderem às demandas da legislação ambiental. Além dos recursos federais, dados de 1998 mostram que 26 estados ofereciam incentivos fiscais e financiavam melhorias como instalações e equipamentos para tratamento de dejetos, do odor, para destinação de animais mortos, proteção dos rios, riachos e solos ${ }^{27}$. A participação dos recursos estaduais variava entre $50 \%$ e $75 \%$ do total emprestado aos suinocultores. Há também incentivos fiscais como redução do imposto de comercialização do produtor, diminuição da taxação

\footnotetext{
${ }^{20}$ A regulamentação é denominada Proposed Revisions to the National Pollutant Discharge Elimination System Permit Regulations and the Effluent Guidelines and Standards for Concentrated Animal Feeding. Pode ser acessada no endereço: http://www.epa.gov/ost/ guide/cafo/. Análises dos impactos na suinocultura podem ser encontradas em USEPA (2001b) , seções 1.1.4 e seção 7, respectivamente.

${ }^{21} \mathrm{Na}$ linguagem técnica conhecido por NPS (non-point pollution source).

${ }^{22}$ As perguntas mais freqüentes (faq) sobre as novas regras estão em http://www.epa.gov/ npdes/pubs/cafo_faq.pdf, sendo que a seção VIII trata dos prazos de implementação.

${ }^{23} \mathrm{~A}$ opinião de produtores pode ser encontrada no site http://industryclick.com/ (solicite busca do termo EPA Plan). Uma noção da polêmica em torno da eficiência da regulação de 2002 pode ser vista em MO \& ABDALLA (1998) e Metcalfe (2000b).

${ }^{24}$ A opinião deste grupo sobre a regulamentação aprovada em 1992 pode ser vista em http://www.farmweb.org/ .

${ }_{25}$ Para uma visão do Farm Bill 2002, acesse http://www.usda.gov/farmbill/.

${ }^{26}$ Conforme jornal Washington Post em 14/05/2002, página AO1, que pode ser lido no site http://www.washingtonpost.com/wp-dyn/articles/A11478-2002May13.html .

${ }^{27}$ Conforme a pesquisa National Survey of Animal Confinement Policies. As questões número 39 e 40 tratam deste assunto. Os resultados estão no site http://cherokee.agecon. clemson.edu/confine.htm e.
} 
à propriedade rural e menor alíquota do imposto incidente na compra de equipamentos para tratamento e controle de dejetos.

\subsection{Características econômicas da regulamentação da suinocultura americana}

A regulamentação tem impacto nos custos da suinocultura. A participação dos insumos ambientais varia entre $1 \%$ a $8 \%$ do custo total, correspondendo a US\$ 0,40 e US 3,20 por animal (METCALFE, 2000a). Estes custos podem inviabilizar a atividade de pequenos e médios produtores, que atuam com pequenas margens de ganho, porém podem ser absorvidos por ganhos de escala nos grandes empreendimentos.

BOEHLJE et al. (1997) revelam dados sobre a tendência de concentração nos grandes empreendimentos. Por exemplo, entre 1980 e 1996, três de cada quatro produtores norte-americanos desistiram da atividade, e em apenas cinco anos (1993-1998), a participação de unidades com mais de 2000 animais confinados ampliou-se de $28 \%$ para $63,5 \%$ do total. Cerca de $40 \%$ desta expansão ocorreu no Estado da Carolina do Norte (METCALFE, 1999). Os Estados de Iowa e Minnesotta contém o maior número de unidades com mais de 5.000 animais $^{28}$, as quais também são responsáveis pela quase totalidade da produção nos Estados do Colorado, Oklahoma e Texas (SULLIVAN et al., 2000).

A regulamentação também está associada à mobilidade espacial da suinocultura americana. Estados com densidade populacional baixa atraem as grandes explorações porque são menores as chances de denúncias de eventuais externalidades, que tem repercussão negativa junto ao mercado (ROE et al., 2002). O atual crescimento da suinocultura tem se dado nos estados do Oeste, como Colorado, Utah e no Sul a exemplo do Texas, os quais possuem vastas áreas pouco povoadas. No caso do Oeste há a vantagem adicional da maior proximidade com os portos da Califórnia, implicando custos menores para exportar para o mercado asiático comparativamente aos portos da região Leste. Os estados da região Sul também têm a vantagem da proximidade com o mercado mexicano. Outros

\footnotetext{
${ }^{28}$ Um mapa dos EUA com a localização dos 50 maiores produtores em 1997 pode ser visto em http://www.agriculture.com/sfonline/sf/1997/october/pork97/media/map97.gif
} 
Externalidades e mudanças da regulamentação ambiental para a suinocultura norte-americana: é possível no caso brasileiro?

fatores são importantes para explicar o deslocamento da produção como incentivos, infraestrutura, capacidade de abate, alianças entre produtores e agroindústrias e entre processadores, menores custos de produção, de processamento e de distribuição (BOEHLJE et al., 1997:18).

\section{Avaliação da regulamentação da suinocultura brasileira à luz da experiência norte-americana}

Nesta seção destacam-se características associadas à regulação ambiental da suinocultura norte americana para se avaliar a possibilidade da legislação ambiental brasileira ser modificada, acompanhando a tendência dos países desenvolvidos.

\subsection{Características institucionais da regulamentação}

A regulamentação americana compõe-se da atuação de agências federais e estaduais, que se complementam na questão do licenciamento da atividade suinícola. Este fato possibilita que a instituição federal, EPA, defina padrões que melhor se ajustem às características evolutivas do processo produtivo na suinocultura.

Não há similaridade da legislação federal americana nas instituições brasileiras. Possivelmente o Plano Nacional de Recursos Hídricos ${ }^{29}$ seja o documento legal mais próximo, o qual trata de um roteiro de procedimentos e regras sobre os cursos d'água em geral. Nos estados, as respectivas organizações públicas ambientais usam padrões diferentes, que tratam basicamente das distâncias das unidades produtoras aos mananciais de água, e que devem ser observados por ocasião do licenciamento do produtor.

No caso de uma legislação única, padronizadora, o governo federal, à semelhança do americano, deveria tomar a iniciativa de definir os padrões mínimos para licenciamento ambiental dos produtores. Esta providência desestimularia que estados competissem entre si, através de licenciamentos menos restritivos, para atrair investimento no setor, e também ofereceria maior certeza do controle do impacto ambiental das atividades.

${ }^{29}$ O plano pode ser localizado no site http://www.mma.gov.br/. 
Outro aspecto é que houve muitos problemas ambientais, apesar da legislação severa no controle dos dejetos da suinocultura norte-americana, os quais, em grande parte, se deveram à falta de fiscalização e punição pelas autoridades. Isto mostra que modificação na legislação para torná-la mais eficiente precisa de recursos para fazer valer seus preceitos. Sem os mesmos há o risco de ocorrer o colapso regulatório, como, por exemplo, em Santa Catarina, onde a agroindústria é credenciada pelo governo para elaborar e acompanhar os pedidos de licenciamento ambiental dos produtores integrados. Se a regulamentação é custosa aos produtores, e cuja implantação pode reduzir a oferta de animais para o abate, então a agroindústria pode não ter interesse no cumprimento das regras.

\subsection{Características sociais da regulamentação}

A regulamentação americana em grande parte resulta do embate, de um lado, dos interesses das comunidades e grupos sociais relacionados com a sustentabilidade ambiental e direitos de propriedade dos cidadãos afetados pelas externalidades da suinocultura, e de outro pelos interesses econômicos de autoridades, produtores e agroindústria.

Não existe a oposição organizada do terceiro setor (social empowerment) no Brasil. O processo de crescimento econômico parece ainda não ser suficiente para que a comunidade em geral veja as externalidades como um 'mal necessário' das atividades econômicas. A dependência econômica de inúmeras comunidades interioranas aos ganhos da atividade suinícola possivelmente explique esta visão, já que uma regulamentação mais restrita implicaria maiores custos e menores ganhos.

Daí, que pressões para modificações na regulamentação ambiental brasileira provavelmente surjam de organizações ligadas ao setor como centros de pesquisa e de assistência aos produtores em nível estadual e federal, ONG's e universidades.

\subsection{Características econômicas da regulamentação}

A regulamentação ambiental mais severa para a atividade suinícola norte-americana é um componente impactante nos custos da atividade, tendo em vista a necessidade de tecnologias e infraestrutura visando 
o depósito e a utilização dos dejetos. A busca de economias de escala é a alternativa para absorver estes custos, e a outra maneira é utilizar recursos públicos baratos e isenções fiscais visando reduzir o impacto financeiro das despesas com insumos ambientais.

Na suinocultura brasileira o avanço das economias de escala no setor ainda não tem a dimensão da norte-americana. Entre 1994 e 2000 o número mínimo de animais recomendados para uma granja aumentou $33 \%$, de 150 para 200 (PINAZZA \& ALIMANDRO, 2000). Estima-se que a produção dos quase 70.000 suinocultores do Oeste catarinense em 1980 poderia ser obtida por apenas um terço dos produtores no prazo de 20 anos (TESTA et al., 1996). Portanto, dada a tendência de concentração em explorações maiores, é possível prever que haverá um aumento significativo da poluição por dejetos com o crescimento do setor.

Daí que a modificação das regras ambientais tende ser uma necessidade futura devido às características econômicas e polutivas da atividade. Além disso, a regulamentação deve ter a característica de prever recursos, seja na forma de crédito ou isenção fiscal, que facilitem ao produtor a compra de insumos.

\section{Conclusões}

Neste estudo descreveu-se a suinocultura norte-americana com destaque para as externalidades, direito de propriedade, mobilização social e regulamentação ambiental para avaliar a possibilidade de modificação das regras brasileiras.

A análise evidenciou que se a reforma fosse feita aos moldes da norte-americana teria que ser uma iniciativa do governo federal para definir metas nacionais de padrões polutivos por dejetos com base na consolidação das regulamentações estaduais. Também seriam necessários recursos públicos para fiscalizar e punir poluidores e para financiar os produtores na aquisição dos insumos ambientais. Por outro lado, os interesses da sociedade pró-reforma estariam restritos a atuação de organizações isoladas de pesquisa e extensão.

A pressão política destas organizações, entretanto, é contraposta pela percepção comum de que a suinocultura brasileira não tem sérios problemas ambientais. Esta perspectiva dificultaria a alocação de recursos 
públicos para realizar a reforma. Com estas considerações, podemos concluir que atualmente não são reunidas condições sociais, econômicas e institucionais que permitam avaliar como factível a possibilidade de alterar a regulação ambiental da suinocultura brasileira no curto-prazo.

Todavia, o acirramento da concorrência no mercado internacional, através de restrições não tarifárias, pode ser um fator que sinalize ao governo federal alguma urgência na implementação da reforma já que as exportações de carne suína poderiam ser prejudicadas com reflexos negativos na geração de renda e emprego do setor.

Dada a tendência do setor de crescimento concentrado em grandes explorações, e, por conseqüência, do aumento da poluição por dejetos, então barreiras à expansão do setor podem surgir em estados onde o problema ambiental já está instalado, a exemplo de Santa Catarina. Daí, a alteração da regulamentação ambiental nos estados tenderia anteceder à iniciativa federal, como ocorrido no setor norte-americano.

Enquanto isso, aos estados cabe intensificar o monitoramento da poluição por dejetos visando o aperfeiçoamento legislativo paralelamente à evolução tecnológica do setor. A pesquisa pública deve buscar o desenvolvimento de tecnologias para deposição e tratamento dos dejetos com custos acessíveis aos produtores. Igualmente o serviço de assistência técnica tem na educação do suinocultor a possibilidade de conscientizálo da atitude correta com o destino dos dejetos.

Sugere-se como pesquisa a avaliação do impacto na competitividade dos principais estados produtores de suínos da adoção de regras ambientais mais adequadas, equivalentes à norte-americana, por exemplo.

\section{Referências bibliográficas}

BEGHIN, J.; METCALFE, M.(1998) Environmental Regulation and Competitiveness in the Hog Industry. An International Perspective. Department of Economics, Iowa State University. (www.econ.iastate.edu/research/ webpapers/ndn0011.pdf)

BOEHLJE, M.; CLARK, K.; JONES, C.H.D.; MILLER, A.; SINGLETON, B.R.W. \& SCHINCKEL, A. (1997). Food System 21: Gearing up for the New Millenium - The Hog/Pork Sector. Staff Paper 97-19, Department 
of Agricultural Economics, Purdue University, December. (http: agecon. lib.umn.edu/index.html). Accessed 11/2000.

ARROW, K et al. (1995). Economic growth, carrying capacity and the environment. Science.n.268, April.

BURTON, M; RIGBY, D; YOUNG, T; SOUZA FILHO, H.M.(1998). Adoção de tecnologias sustentáveis no Paraná. Revista de Economia e Sociologia Rural, vol.36, ${ }^{\circ} 4$, outubro/dezembro. Brasília, DF: Sociedade Brasileira de Economia e Sociologia Rural (SOBER).

CARVALHO, F. J.C. (1999). Mercado, estado e teoria econômica. Uma breve reflexão. Revista Econômica, vol.1, no.1, Niterói, RJ.: Pós-graduação em Economia, Universidade Federal Fluminense, junho.

CAMPOS, I. (1995). Complexos de Produção Agroindustrial e Mecanismos de Formação de Preços na Agricultura. Anais do Encontro Nacional de Economia (ANPEC), Salvador, volume 1, 572-589.

COASE, R. (1960). The problem of social cost. Journal of Law and Economics, vol. 3,(October); pp.1-44.

COLMAN, D. (1993). Environmental economics and agricultural policy. In Current Issues in Agricultural Economics. Edited by A.J. Rayner and David Coman. London: Macmillan Press Ltd.

EGGERTSOON, T. (1994). Economic behavior and institutions. New York: Cambridge University Press.

GOLLEHON, N. e CASWELL, M. (2000). Confined Animal Production Poses Manure Management Problems. Agricultural Outlook. Economic Research Service, USDA, Setembro. (http://www.ers.usda.gov/publications/agoutlook/sep2000/ao274f.pdf) Acessado em 13/05/2002.

GONÇALVES, R. (1998). Meio Ambiente e a Economia Política do Comércio Internacional. Revista da Sociedade Brasileira de Economia Política, Rio de Janeiro, no. 3, dezembro, p. 101-113.

McMAHON, K., VANSICKLE, J. e DUXBURY-BERG, L. (1998). State of the Industry . National Hog Farmer, May 15, p. 16 -34. (http://industryclick. com/magazine.asp?siteid $=5 \&$ magazineid $=17$ ) Acessado em 10/2001 . 
METCALFE, M. (1999). Location of Production and Water Quality Regulation: the U.S. Hog Industry. Selected Paper presented at the Annual Meeting of the American Agricultural Economics Association, 1999.

METCALFE, M. (2000). State Legislation Regulating Animal Manure Management. Review of Agricultural Economics, volume 22, número 2, Fall / Winter. (http://www.aaea.org/fund/pubs/rae). Acessado em 02/05/2002.

METCALFE, M. (2000a). Environmental Regulations and Implications for U.S. Pork Exporters. 2000 Annual Meeting of the American Agricultural Economics Association.

MMA (Ministério do Meio Ambiente). (2001). Comércio e Meio Ambiente. Uma Agenda para a América Latina e Caribe. Coordenação Antonio Sérgio Braga. Brasília, MMA, Secretaria de Políticas para o Desenvolvimento Sustentável. (http://www.mma.gov.br) Acessado em 02/2002.

MO, Y. e ABDALLA, C. W. (1998). Analysis of Swine Industry Expansion in the U.S.: the Effect of Environment Regulation. Agricultural Law Update, 15 August, pp.4-7. Resumo do artigo pode ser acessado em http://coldfusion.aers.psu.edu/aerec/graduates.cfm.

MUELLER, Charles (1998). Avaliação de duas correntes da economia ambiental: escola neoclássica e a economia da sobrevivência. Revista de Economia Política, vol.18, ${ }^{\circ}{ }^{2}$, abril-junho. São Paulo, SP. (http:// www.rep.org.br/pesquisar.asp)

OECD (Organization for Economic Co-operation and Development) (1994). Towards sustainable agricultural production: Cleaner technologies. Paris

PINAZZA, L.A. e ALIMANDRO, R. (2000). Posição Consolidada. Agroanalysis, FGV, Rio de Janeiro, julho.

RHODES, V.J. (1998). The Industrialization of Hog Production. In The Industrialization of Agriculture. Vertical Coordination in the U.S. Food System. Jeffrey Royer and Richard Rogers (editors). Brokfield, Ashgate Publishing Company.

ROE, B.; IRWIN, E.G. e SHARP, J. S. (2002). Pigs in Space: Modeling the 
Spatial Structure of Hog Production in Traditional and Nontraditional Production Regions. American Journal of Agricultural Economics, 84 (2), May, 259-278. (http://www.ingenta.com/journals/browse/bpl/ajae). Acessado em 05/05/2002.

ROMEIRO, Ademar (1999). Desenvolvimento sustentável e mudança institucional: notas preliminares. Revista Econômica, vol.1, $\mathrm{n}^{0}$ 1, junho. Curso de pós-graduação em Economia da Universidade Federal Fluminense. Niterói, RJ: (http://www.uff.br/cpgeconomia/)

SANTANA, E. A. (1995). Teoria do agente-principal, regulação e performance da indústria de energia elétrica no Brasil. Anais do XXIII Encontro Nacional de Economia, vol. 1. Rio de Janeiro: Associação Nacional dos Cursos de Pós-Graduação em Economia (ANPEC), p. 403-421.

SCHRADER, L.F. (1998). Coordination in the United States Hog / Pork Industry. Staff Paper \#98-19. Department Agricultural Economics, Purdue University. (http://agecon.lib.umn.edu/index.html) Acessado em 05/2001.

SULLIVAN, J.; VASAVADA, U. e SMITH, M., (2000). Environmental Regulation and Location of Hog Production. USDA, ERS, Agricultural Outlook, Sept, pp 19-23. (http:// www.ers.usda.gov/publications/agoutlook/Sep2000/ao274g.pdf). Acessado em 11/02/2002.

TESTA, V.M.; NADAL,R.; MIOR,L.C.; BALDISSERA, I.T.; CORTINA, N. (1996). O_Desenvolvimento Sustentável do Oeste Catarinense (Proposta para Discussão). Florianópolis, Epagri.

USEPA (United States Environment Protection Agency). (2001a). States Compendium. Programs and Regulatory Activities related to Animal Feeding Operations. EPA.

USEPA (United States Environment Protection Agency). (2001b). Economic Analysis of the Proposed Revision to the National Pollutant Discharge Elimination System Regulation and the Effluent Guidelines for Concentrated Animal Feeding Operations. (http://www.epa.gov/ost/ guide/cafo/economics.html). Acessado em 09/2001.

USEPA (United States Environment Protection Agency). (2001c). Environment Assessment for the Proposed Revision to the National Pollutant Discharge Elimination System Regulation and the Effluent Guidelines for 
Concentrated Animal Feeding Operations. (http://www.epa.gov/ost/guide/cafo/envir.html). Acessado em 09/2001.

VARIAN, H. R. (1994). Microeconomia. Princípios básicos. 2a . Ed. Tradução de Luciane Melo. Rio de Janeiro: Campus.

VASCONCELOS, M.A.S.; OLIVEIRA, R.G. (2000). Manual de microeconomia. São Paulo, Atlas.

WEYDMANN, C.L. (2002). Análise Comparada de Políticas Ambientais para a Suinocultura. Revista de Política Agrícola, Secretaria de Política Agrícola, Ministério da Agricultura, Pecuária e Abastecimento, jul/ago/ set,2002, p.33-40. (http://www.agricultura.gov.br/spa/spa_03.htm)

Recebido em março de 2003 e revisto em junho de 2004. 